\title{
UV Absorbing Property of Ageratum conyzoides Linn Leaves
}

\author{
Tanaya Ghosh ${ }^{1}$, Prasenjit Mitra ${ }^{2}$ and Prasanta Kumar Mitra ${ }^{1 *}$ \\ ${ }^{1}$ Department of Medical Biotechnology, Sikkim Manipal University, Sikkim Manipal \\ Institute of Medical Sciences, Gangtok, Sikkim, India \\ ${ }^{2}$ Department of Biochemistry, All India Institute of Medical Sciences (AIIMS), \\ Jodhpur, Rajasthan, India \\ *Corresponding Author: Prasanta Kumar Mitra, Professor and Head, Department \\ of Medical Biotechnology, Sikkim Manipal University, Sikkim Manipal Institute of \\ Medical Sciences, Gangtok, Sikkim, India.
}

Received: February 19, 2020

Published: February 27, 2020

(C) All rights are reserved by Prasanta Kumar Mitra., et al.

\begin{abstract}
Ageratum conyzoides Linn (A. conyzoides L.) is a medicinal plant. The plant contains numerous phytochemicals which have shown diverse pharmacological activities such as analgesic, allelopathy, antimicrobial, antioxidant, antidiabetic, anticancer, antiprotozoal, spasmolytic, anti-inflammatory and many more. Aim of the present study was to examine UV absorbing property of $A$. conyzoides $\mathrm{L}$. leaves, if any. Leaves of $A$. conyzoides $\mathrm{L}$. were collected and identified by the taxonomist. Solvent extractions of the leaves were made separately by using chloroform, acetone, methanol, ethanol, benzene and ethyl acetate. The extractions were separately exposed for absorption of UV ray in a spectrophotometer using UV region $(200-400 \mathrm{~nm})$. Result showed that all solvent extracts of the leaves had UV absorbing property but ethanol extract had maximum activity. Ethanol extract of $A$. conyzoides L. leaves may be further studied for isolation of the active compound(s) responsible for UV absorbing property.

Keywords: Ageratum conyzoides Linn. Leaves; Solvent Extractions; UV Absorbing Property
\end{abstract}

\section{Introduction}

A. conyzoides L. (family, Asteraceae), one of the medicinal plants, grows commonly in the proximity of habitation. The plant thrives in any garden soil and is very common in waste places and on ruined sites [1]. A. conyzoides L. is distributed throughout India, lower and middle hill in Sikkim and Darjeeling up to $6000 \mathrm{ft}$. The plant has erect hairy annual $30-90 \mathrm{~cm}$ high leaves. A. conyzoides L. is known by different names. In Nepali the plant is called 'Elame', in Lepcha and English the plant is known as 'Namyew' and 'Goat weed respectively'. Throughout year the plant gives flower. Purple white flower appears [2].

Since ages $A$. conyzoides L. has been used in different folkloric system of medicine to treat a variety of diseases such as, malaria, stomach ailments, pneumonia, wounds, boils, sore throat, skin disorders, sleeping sickness, chronic ulcer, intra-uterine problems, frontal headache, rheumatism, colic etc. [3]. Use of the plant as emetic, purgative, febrifuge, antispasmodic and antiasthmatic is mentioned in Ayurveda, Charaka Samhita and Sushruta Samhita. Leaves, root, stem and flower of A. conyzoides L. are widely utilized in traditional medicine. Leaves are styptic effective in healing of wounds, use in boils and prevent tetanus. Leaf juice is also used as eye lotion. The root juice has antibiotic property. The plant is boiled with oil and applied externally in rheumatism [4].

Phytochemicals identified and characterized in A. conyzoides L. are many. These include 4 '-hydroxy-5,6,7,8,3'-pentamethoxyfla- vone, 4'-hydroxy-5,6,7,8,3',5'-hexamethoxyflavone, 5,6,7,8,3'-pentamethoxy-4', 5,6,7,5'-tetramethoxy-3',4'-methylenedioxyflavone, 5'-methylenedioxy flavone, 5,6,7,8,3',4'-hexamethoxyflavone (nobiletin), 5,6,7,8,3',4',5'-heptamethoxyflavone (5'-methoxynobiletin), $5,6,7,3^{\prime}, 4^{\prime}{ }^{\prime}$ '-hexamethoxy flavone etc. as flavonoids and sabinene acetate, $\beta$-sesquiphellandrene, camphene, carvacrol, p-cymene, linalool, carvacryl acetate, sabinene, $\beta$-bourbonene, cis- $\beta$-guaiene, $\alpha$ - and $\beta$-cubebene, $\alpha$ - and $\beta$-farnesene, farnesol etc. as terpenoids. Other compounds like 6-vinyl,7-methoxy-2,2-dimethylcromene, 6-(1-methoxyethyl)-7-methoxy-2,2-dimethyl chromene, encecanescins, 6-(1-ethoxyethyl)-7-methoxy-2,2-dimethylchromene, 6-(1-hydroxy ethyl)-7-methoxy-2,2-dimethylchromene and phydroxybenzoic acid, p-coumaric acid, fumaric acid, gallic acid, coumalic acid, protocatechuic acid, resorcinol, hexadecanoic acid, sinapic acid, benzoic acid, cis-hexen-3-en-1-ol, phenyl ethyl acetate, methanazulene and tricycoundecane were also identified in various parts of the plant [5].

A. conyzoides $\mathrm{L}$. has a wide range of pharmacological activities like antidiabetic, antitumor, antidotal, antioxidant, antimicrobial, anthelmintic, antiulcerogenic, analgesic, cytotoxic, hepatoprotective, anticonvulsant, radioprotective, antiprotozoal, allelopathic, insecticidal, haematopoietic, wound healing, gastroprotective, anti-inflammatory, anti-cataleptic etc. [6]. UV Absorbing Property of A. conyzoides, L. however, is not known in available literature. The present work was, therefore, undertaken to know UV absorbing property of $A$. conyzoides L. leaves, if any. 


\section{Methodology}

Plant material

A. conyzoides L. leaves were collected in morning hours (9 - 10 AM) from the medicinal plants garden of the University of North Bengal, Siliguri (26041'30.9984" N, 88027'4.5756" E, elevation, $410 \mathrm{ft}$ ), Dist. Darjeeling, West Bengal, India sometimes in the month of April, 2019. Leaves were authenticated by the taxonomist of the department of Botany of the University of North Bengal, Siliguri. A voucher specimen (No. SM-MB-08) was kept in the department of Medical Biotechnology, Sikkim Manipal Institute of Medical Sciences of Sikkim Manipal University, Gangtok, Sikkim, India for future references.

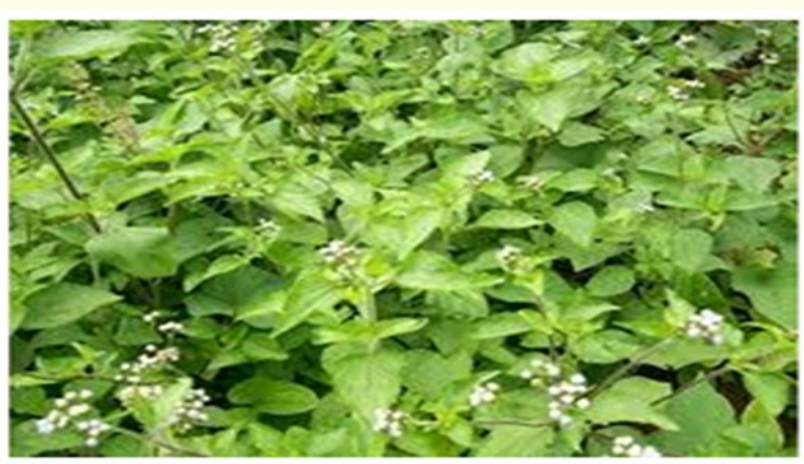

A. conyzoides $\mathrm{L}$.

Figure a

\section{Extraction of the plant leaves}

Collected A. conyzoides L. leaves were washed thoroughly. Leaves were then shade dried and powdered. $50 \mathrm{~g}$ of this powder were extracted separately with $500 \mathrm{ml}$ of methanol, ethanol, acetone, chloroform, benzene and ethyl acetate in a soxhlet apparatus at $37^{\circ} \mathrm{C}$ for 15 minutes. Mixture was then filtered. Filtrate was made to dryness by using lyophilizer. Brown mass obtained.

\section{Determination of UV absorbing property}

$10 \mathrm{mg}$ of the brown mass was dissolved in $100 \mathrm{ml}$ distilled water. The solution was processed in a spectrophotometer for UV ray absorption at the range of $200-400 \mathrm{~nm}$ at $10 \mathrm{~nm}$ intervals.

\section{Chemicals}

Chemicals required for the study were purchased from Loba Chem. Lab, Himedia Lab, India and from Merck, Germany

\section{Statistical analysis}

All experiments were repeated for three times. Data were analysed statistically by SPSS 20 . The statistical significance between UV absorption spectra of different extracts was evaluated with Duncan's multiple range test (DMRT). $5 \%$ were considered to be statistically significant [7].

\section{Results and Discussion}

UV absorption spectra of chloroform extract of $A$. conyzoides $\mathrm{L}$. leaves is shown in figure 1. Chloroform extract absorbs maximum UV ray at $200 \mathrm{~nm}$ (1.1). UV ray absorptions by the same extract at $250 \mathrm{~nm}, 300 \mathrm{~nm}, 350 \mathrm{~nm}$ and $400 \mathrm{~nm}$ were $0.61,0.52,0.39$ and 0.25 respectively. Figure 2 shows UV absorption spectra of acetone extract of $A$. conyzoides L. leaves. At $200 \mathrm{~nm}$ wave length acetone extract absorbs maximum UV rays (0.92). At $250 \mathrm{~nm}, 300 \mathrm{~nm}, 350 \mathrm{~nm}$ and $400 \mathrm{~nm}$ wave length acetone extract of $A$. conyzoides $\mathrm{L}$. leaves showed absorption $0.52,0.41,0.31$ and 0.21 respectively.

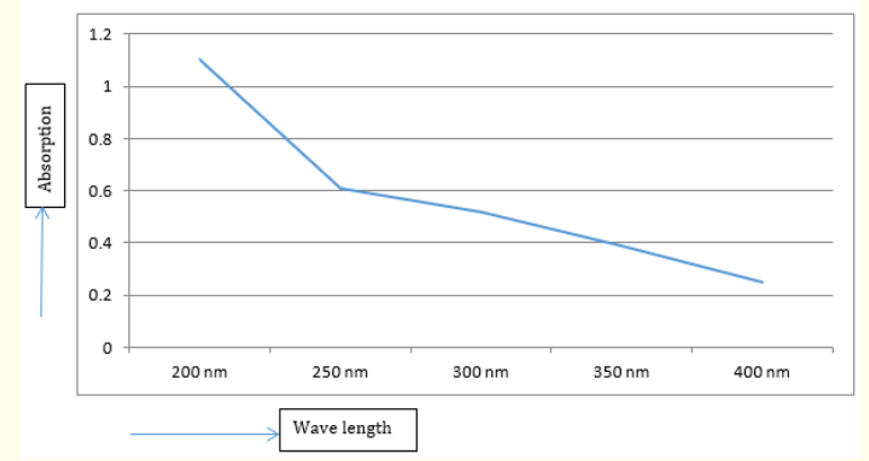

Figure 1: UV radiation absorption by the chloroform extract of $A$. conyzoides $\mathrm{L}$. leaves.

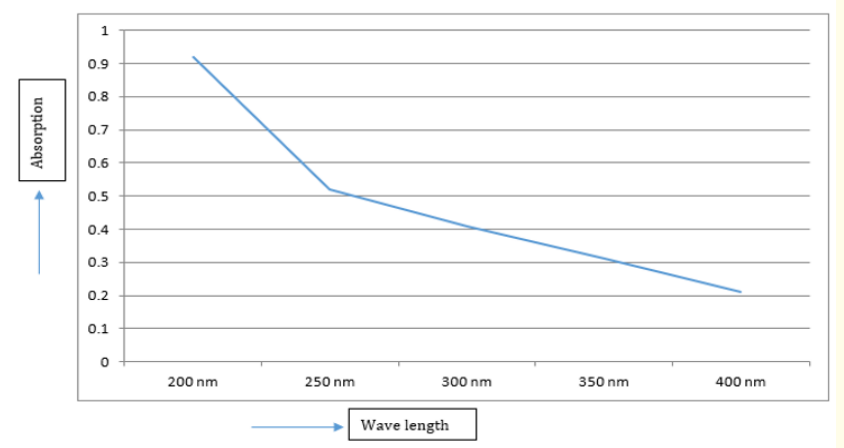

Figure 2: UV radiation absorption by the acetone extract of $A$. conyzoides L. leaves.

UV absorption spectra of methanol extract of $A$. conyzoides $\mathrm{L}$. leaves is shown in figure 3. Methanol extract showed maximum UV absorption at $200 \mathrm{~nm}$ (1.41). UV ray absorptions by the same extract at $250 \mathrm{~nm}, 300 \mathrm{~nm}, 350 \mathrm{~nm}$ and $400 \mathrm{~nm}$ were 0.740 .61 , 0.42 and 0.31 respectively. Figure 4 shows UV absorption spectra of ethanol extract of $A$. conyzoides L. leaves. At $200 \mathrm{~nm}$ ethanol extract absorbs maximum UV rays (1.67). At $250 \mathrm{~nm}, 300 \mathrm{~nm}, 350 \mathrm{~nm}$ and $400 \mathrm{~nm}$ wave length ethanol extract of $A$. conyzoides $\mathrm{L}$. leaves however showed absorption $0.92,0.73,0.52$ and 0.33 respectively. 


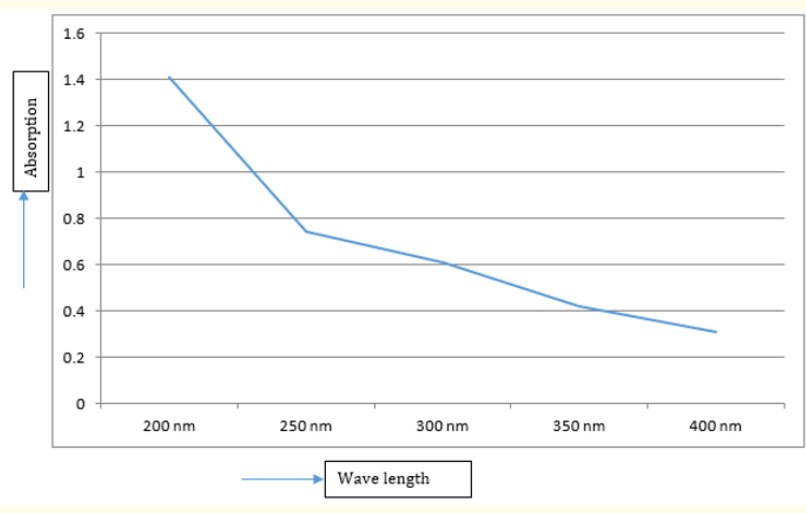

Figure 3: UV radiation absorption by the methanol extract of $A$. conyzoides L. leaves.

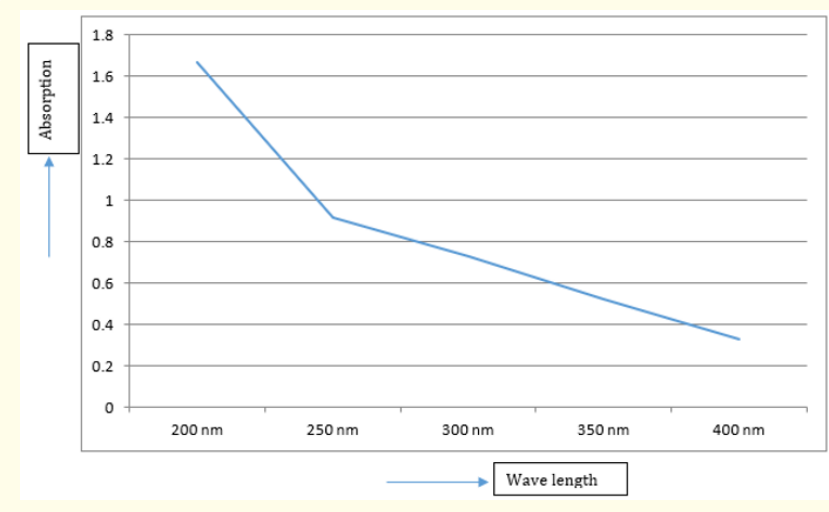

Figure 4: UV radiation absorption by the ethanol extract of $A$. conyzoides L. leaves.

UV absorption spectra of benzene extract of $A$. conyzoides $\mathrm{L}$. leaves is shown in figure 5. Benzene extract showed maximum UV absorption at $200 \mathrm{~nm}(0.62)$. UV ray absorptions by the same extract at $250 \mathrm{~nm}, 300 \mathrm{~nm}, 350 \mathrm{~nm}$ and $400 \mathrm{~nm}$ were $0.41,0.39,0.25$ and 0.11 respectively.

UV absorption spectra of ethyl acetate extract of $A$. conyzoides L. leaves is shown in figure 6. Ethyl acetate extract showed maximum UV absorption at $200 \mathrm{~nm}(0.41)$. UV ray absorptions by the same extract at $250 \mathrm{~nm}, 300 \mathrm{~nm}, 350 \mathrm{~nm}$ and $400 \mathrm{~nm}$ were $0.28,0.21$, 0.15 and 0.07 respectively.

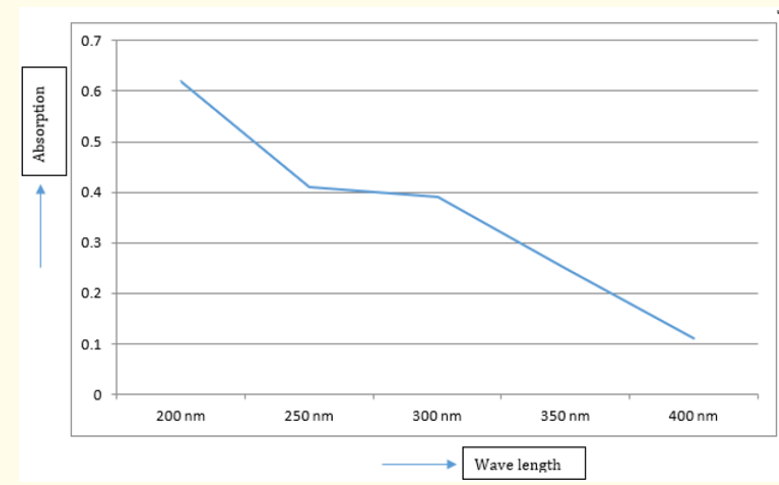

Figure 5: UV radiation absorption by the benzene extract of $A$. conyzoides $\mathrm{L}$. leaves.

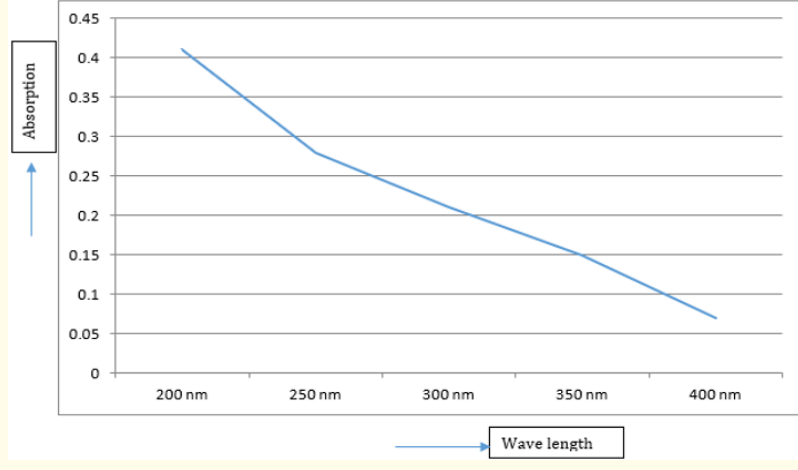

Figure 6: UV radiation absorption by the ethyl acetate extract of $A$. conyzoides L. leaves.

\section{Discussion}

UV (ultraviolet) radiation, falls under 180 - $400 \mathrm{~nm}$ wavelength region of the electromagnetic spectrum, is the non-ionizing radiation. Ultraviolet radiation is divided into three regions: UVA known as black light (wave length, 315 - $400 \mathrm{~nm}$ ), UVB known as erythemal (wave length, $280-314 \mathrm{~nm}$ ) and UVC known as germicidal (wave length, 180 - $280 \mathrm{~nm}$ ). Main source of UV radiation is sunlight though UV radiation also generates in the laboratory through crosslinkers, transilluminators, biological safety cabinets, lasers, germicidal lamps etc. So, there are ample scope to get exposure of ultraviolet radiation by the human body [8]

Solar UV-radiation is good for humans because the radiation is required for cutaneous synthesis of vitamin D. And, this covers almost $90 \%$ of the vitamin D-requirements of the body, But UV radiation has adverse effects too. UV-radiation comes from sun is the most important environmental risk factor for development of non-melanoma skin cancer. UVB radiation causes pigmentation, sunburn, immune-suppression and photo carcinogenesis. Both UVA and UVB can cause erythema and inflammation, sunburn and photo ageing. Other detrimental effect of UV exposure is photosensitivity reactions to ingested drugs [9]. Efforts are therefore made to invent sources through which solar/artificial UV rays can be absorbed [10]. In this context work has been extended even to the field of medicinal plants [11].

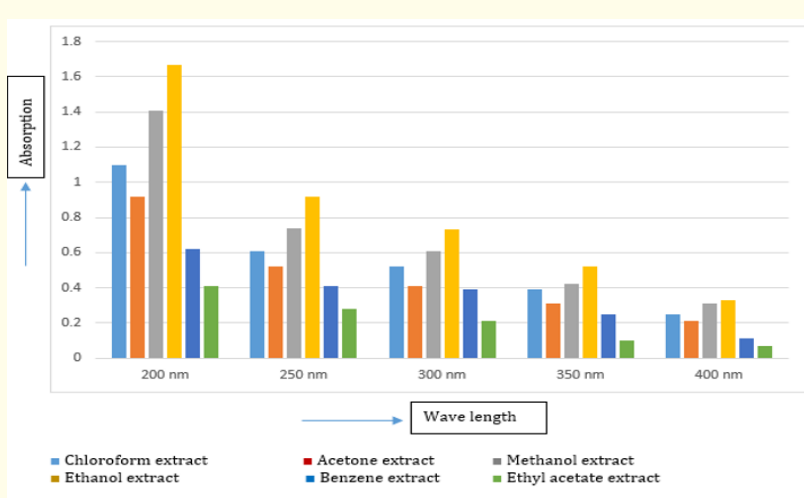

Figure 7: UV radiation absorption by the chloroform, acetone, methanol, ethanol, benzene and ethyl acetate extracts of $A$. conyzoides L. leaves. 
Several medicinal plants have shown UV absorption property. Few are, Atalantia ceylanica, Hibiscus furcatus, Leucas zeylanica, Mollugo cerviana, Olax zeylanica, Ophiorrhiza mungos as well as many others [12]. In the present study we have shown, probably for the first time, UV radiation absorption property of A. conyzoides L. leaves. Chloroform, acetone, methanol, ethanol, benzene and ethyl acetate. extracts of $A$. conyzoides L. leaves showed UV radiation absorption property for all wave lengths of UV region but major amount of absorption was found in between $200-300 \mathrm{~nm}$ that is at UVC region (180 - $280 \mathrm{~nm})$. Further, ethanol extract of $A$. conyzoides L. leaves showed maximum UV radiation absorption in all UV regions (Figures, 1-6 and 7).

It is known that biological activities of medicinal plant depend on temperature and time of extraction process [13-18]. It is, therefore, worth to investigate effect of temperature and time of extraction process on UV absorption property of $A$. conyzoides L. leaves. Work is this direction is now in progress.

\section{Conclusion}

Present study showed that ethanol extract of $A$. conyzoides $\mathrm{L}$. leaves had maximum UV absorbing property. Ethanol extract of $A$. conyzoides L. leaves may, therefore, be further studied for isolation of the active compound responsible for UV absorbing property.

\section{Recommendation}

Ethanol extract of $A$. conyzoides L. leaves may be used as UV radiation absorbing material.

\section{Acknowledgement}

We gratefully acknowledge the cooperation of taxonomists of the department of Botany, University of North Bengal, Siliguri, Dist. Darjeeling, West Bengal for identification of A. conyzoides L. leaves.

\section{Conflict of Interest}

Nil.

\section{Bibliography}

1. Chopra Col Sir RN and Chopra IC. Indigenous drugs of India, U. N. Dhar and Sons Private Limted, Kolkata (1958): 668.

2. Handa SS and Vasisht K. Compendium of Medicinal and Aromatic Plants-Asia, II, ICS- UNIDO, Area Science Park, Padriciano, Trieste, Italy. (2006): 79-83.

3. Pullaiah T. Encyclopaedia of world medicinal plants. New Delhi (India): Regency Publications (2006)

4. Vaidyaratnam Varier PS. Indian Medicinal Plants - A Compendium of 500 species, I, Orient longman publishing house, Kottakkal-India. (2002); 146.

5. González AG., et al. "Chromenes from Ageratum conyzoides". Phytochemistry 30 (1991): 1137-1139.
6. Kaur R and Dogra NK. "A Review on Traditional Uses, Chemical Constituents and Pharmacology of Ageratum conyzoides L. (Asteraceae)". International Journal of Pharmaceutical and Biological Archives 5.5 (2014): 33-45.

7. Bliss CI. "Statistics in biology, Statistical methods for research in the natural Sciences". McGraw Hill Book Company, NY 1 (1967): 558.

8. MacKie RM. "Effects of Ultraviolet Radiation on Human Health". Radiation Protection Dosimetry 91.1 (2000): 15-18.

9. Elwood JM and Jopson J. "Melanoma and sun exposure: An overview of published studies". International Journal of Cancer 73 (1997): 198-203.

10. Gupta Vandana., et al. "Environment friendly antibacterial and uv protective finish on cotton using S. cumini (1.) leaves extract". International Journal of Textile and Fashion Technology 7.1 (2017): 53-62.

11. Gharge VG and Yadav A. "Study of Methanolic Extract of Leaves Calotropis gigantean (L.) As an Anti-Solar". Advances in Complementary and Alternative Medicine 1.4 (2018): 1-3.

12. Napagoda MT., et al. "Photoprotective potential in some medicinal plants used to treat skin diseases in Sri Lanka". BMC Complementary and Alternative Medicine 16 (2016): 479-502.

13. Hamzah., et al. "Effect of extraction time and temperature on the extraction of phenolic compounds from Orthosiphon stamineus leaves". Australian Journal of Basic and Applied Sciences 11.3 (2017): 15-21.

14. Tan., et al. "Effects of extraction solvent system, time and temperature on total phenolic content of henna (Lawsonia inermis) stems". International Food Research Journal 20.6 (2013): 3117-3123

15. Wingard SK and Phillips RC. "Effect of temperature on the rate of extraction of crude oils from vegetable oil seeds with solvents". Journal of the American Oil Chemists Society 28 (1951) 149-152.

16. Sulaiman., et al. "Effects of temperature, time, and solvent ratio on the extraction of phenolic compounds and the anti-radical activity of Clinacanthus nutans Lindau leaves". Chemistry Central Journal 11 (2017): 54-59.

17. Chaowalit M and Chitradee L . "Effect of Temperature and Duration Time of Maceration on Nitrate Content of Vernonia cinerea (L.) Less.: Circumscribed Central Composite Design and Method Validation". International Journal of Food Science 5.1 (2019) 8-15. 
18. Mitra., et al. "Anti Solar Activity of Costus Speciosus Leaves of Sikkim Himalayas: Effects of Time and Temperature on Extraction Process". Scholars Academic Journal of Pharmacy 9.1 (2020): 9-13.

\section{Assets from publication with us}

- Prompt Acknowledgement after receiving the article

- Thorough Double blinded peer review

- Rapid Publication

- Issue of Publication Certificate

- High visibility of your Published work

Website: www.actascientific.com/

Submit Article: www.actascientific.com/submission.php Email us: editor@actascientific.com

Contact us: +919182824667 